\title{
Reasons for parental hesitancy towards Oral Polio Vaccine (OPV): a cross sectional study in Khyber Agency, Pakistan
}

Bibi Aliya, Maryam Karim, Rida Mahnoor, Hina Gul, Seema Ashraf, Umer Humayun, Muhammad Abu Bakar

\section{Submitted}

August 07, 2020

Accepted

September 12, 2020

\section{Author Information}

From: Rehman Medical College, Peshawar, Khyber Pakhtunkhwa, Pakistan.

\section{Dr. Bibi Aliya}

Assistant Professor Department of Community Medicine,

(Corresponding Author)

Email: bibi.aliya@rmi.edu.pk

Maryam Karim

Rida Mahnoor

Hina Gul

Students, Fourth Year MBBS

Dr. Seema Ashraf

Associate Professor

Department of Community

Medicine

Umer Humayun

Muhammad Abu Bakar

Students, Fourth Year MBBS

Citation: Aliya B, Karim M, Mahnoor R, Gul H, Ashraf S, Humayun U, et al. Reasons for parental hesitancy towards Oral Polio Vaccine (OPV): a cross sectional study in Khyber Agency, Pakistan. J Rehman Med Inst. 2020 JulSep;4(4):3-7.

\begin{abstract}
Introduction: Pakistan remains one of the three polioendemic countries in the world due to Illiteracy, religious beliefs, conflicts and security issues hindering vaccination efforts. Parental refusal or hesitancy towards vaccinating their children along with low coverage of polio vaccination in high conflict areas remain key problem areas.
\end{abstract}

Objectives: To assess the awareness regarding polio vaccination, and to identify the reasons of parental hesitancy towards oral polio vaccination.

Materials \& Methods: A cross-sectional survey that included 100 participants was conducted in Jamrud (Khyber Agency) from October 2017 to December 2017. Indigenously structured questionnaire was used for recording data in Khyber Agency through convenience sampling. Questions related to awareness, attitude, practice and reasons for hesitancy regarding polio vaccination. SPSS version 16.0 and Microsoft Excel were used for organizing and analyzing data for descriptive statistics.

Results: Of the 100 study subjects, $49 \%$ were uneducated and only $2 \%$ had a positive family history of polio. Overall awareness regarding polio vaccination was poor; only $27 \%$ of study participants knew that immunization was effective for prevention and $24 \%$ considered vaccine repetition as necessary. The leading reasons given by $24 \%$ were that it causes infertility in male children, $16 \%$ had lack of trust on quality of vaccine, and $16.6 \%$ reported lack of trust on health workers. Religious belief was also one of the reason of hesitancy recorded to be $14.1 \%$. Some participants $(10.7 \%)$ recorded security issues as their reason of vaccine hesitancy. About 9.5\% responded non-compliant spouse as their reason whereas $9.2 \%$ considered that vaccination was not necessary.

Conclusion: Lack of awareness and education were the main reasons behind misperception of subjects towards polio immunization, followed by fears of infertility and religious beliefs.

Keywords: Polio - Global Polio Eradication Initiative (GPEI), Oral Polio Vaccine (OPV), Immunization \& Hesitancy.

The authors declared no conflict of interest. All authors contributed substantially to the planning of research, data collection, data analysis, and write-up of the article, and agreed to be accountable for all aspects of the work.

\section{INTRODUCTION}

Pakistan is one of the three remaining countries (along with Afghanistan \& Nigeria) in the world where poliomyelitis is an endemic viral infection. Although Pakistan started the polio immunization campaign in 1974, efforts for eradication started officially in $1994 .{ }^{2}$ Despite more than hundred rounds of polio vaccination in the last decade, the virus still prevails in the country. Pakistan's Expanded Program on Immunizations (EPI) is in the focus by WHO, of countries that have never stopped transmission of endemic wild poliovirus. ${ }^{3}$

In 1988, WHO launched the campaign of Global Polio Eradication Initiative (GPEI) with an objective to make the world polio-free. ${ }^{1}$ The influence of this initiative was significant as the number of polio cases reduced markedly from an estimated 350,000 cases in 1988 to 359 cases in 2014. Unfortunately, out of these 359 reported cases worldwide in 2014, 306 cases were documented in Pakistan alone. ${ }^{4}$ However, the reported cases of polio in 2015 and 2016 were 54 and 20 , respectively. ${ }^{5}$ It is an alarming situation for the country as the new wave of polio has hit al four provinces of Pakistan. Increased number of polio cases are reported from Khyber Pakhtunkhwa (KP), Federally Administered Tribal Areas (FATA) and Baluchistan. Peshawar division is the most affected area in $\mathrm{KP}$, carrying the major burden of disease. ${ }^{4}$

Vaccine hesitancy denotes refusal or nonacceptance of vaccine despite availability of vaccination services. ${ }^{6}$ Vaccinations are essential in preventing polio, so it is critical for healthcare authorities to know the reasons behind parental vaccine hesitancy. ${ }^{7}$ Harvard Opinion Research Program in cooperation with UNICEF reported after a survey in 2016 that misperceptions of parents about polio virus and oral polio vaccine (OPV), low coverage of OPV in high conflic areas of Pakistan (FATA), and lack of parental trust on local healthcare workers were the main reasons for Polio cases in Pakistan. ${ }^{8}$ It has been suggested that reasons for parental hesitancy vary widely but can be classified into 4 key categories: religious values, personal beliefs, security 
concerns, and a desire for additional knowledge from healthcare workers. ${ }^{7}$ Illiteracy, religious misconceptions, conflict and insecurity in the polio endemic countries have seriously hampered vaccination efforts and have been directly associated with a rise in wild poliovirus transmission with the potential to fail the progress made by the GPEI. ${ }^{9}$ Pakistan is facing the same issues that lead to the failure of global mission of polio eradication, mainly in FATA where children miss oral polio vaccination rounds either due to absence on visits or due to hesitancy of parents. ${ }^{10}$

This research was conducted to analyze the reasons of polio vaccine hesitancy in FATA (Khyber Agency) where total number of polio cases in 2015 were $11 ;^{5}$ the study will provide needed basic information for consideration of interventions required to address this issue.

\section{MATERIALS \& METHODS}

A cross-sectional study was carried out in Jamrud (Khyber Agency) from October to December 2017. A total of 100 male parents were selected from Jamrud districts by convenience sampling. Data were collected through an indigenously structured mixed questionnaire having 4 main parts: the first for socio-demographic data, second for questions regarding awareness, third regarding attitude and practice, and fourth for reasons for parental hesitancy towards polio vaccination. Informed consent was taken from all the parents, ensuring confidentiality. The questionnaire was translated into Urdu, but most of the subjects were illiterate, so data were collected through direct interview in Pushto (local language) based on translation of the questionnaire. Data were analyzed for descriptive statistics on SPSS version 16.

\section{RESULTS}

Of 100 subjects, $22 \%$ were between $18-30$ years, $38 \%$ were between $31-40$ years, $25 \%$ were between $41-50$ years, $13 \%$ were between 51-60 years and 2\% were above 60 years, as shown in Figure 1.

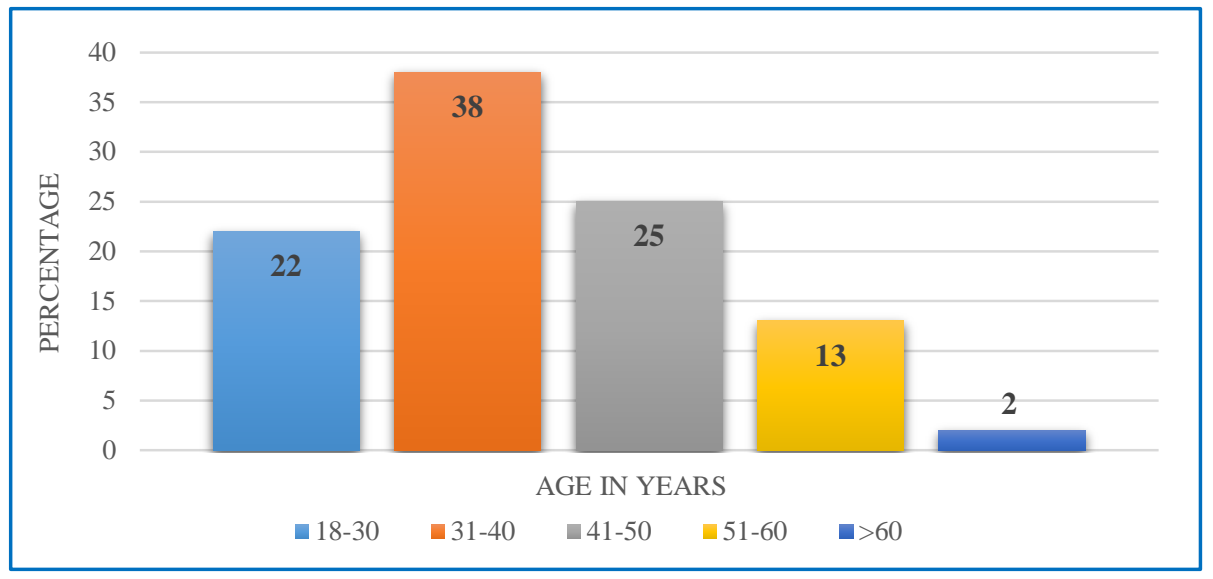

Figure 1: Age (in years) distribution of Respondents ( $n=100)$.

The education level of 100 male parents of Khyber Agency is shown in Figure 2. Majority of them (49\%) were uneducated,

followed by ordinal set of education i.e. primary $38 \%$, secondary $7 \%$, tertiary $1 \%$ and religious $5 \%$.

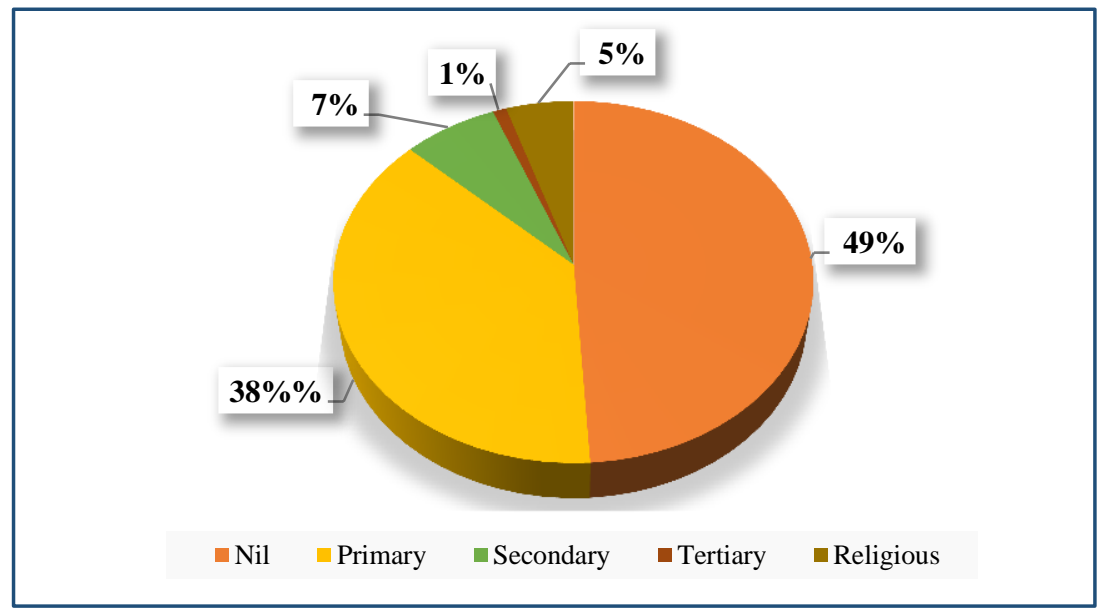

Figure 2: Level of education of respondents $(n=100)$.

Table 1 provides data on knowledge of parents about polio and its vaccination; of 99 parents, 51 knew that along with oral polio vaccine intramuscular preparation was available, while 48 were unaware of it. Knowledge about transmission of polio through contaminated water and feces among the parents was only $21 \%$;
$81 \%$ of respondents were aware that polio can be effectively prevented by immunization, while repetition of vaccine was considered necessary by $72 \%$. Awareness of the fact that polio vaccine should not be administered in illness (diarrhea or fever) came out at $43 \%$, while $75 \%$ were unaware of the fact that 
breastfeeding is not recommended for about 30 minutes after vaccination. A huge gap (88\%) was seen about the knowledge of parents that polio could result in handicap / infantile paralysis.

Table 1: Awareness regarding polio \& vaccination among parents $(n=100)$.

\begin{tabular}{|l|l|l|}
\hline \multicolumn{1}{|c|}{ AWARENESS QUESTIONS } & Yes & No \\
\hline Do you know about that along with oral, intramuscular polio vaccine is also available? (n=99) & 51 & 48 \\
\hline Polio can be transmitted through contaminated water and feces? & 21 & 79 \\
\hline Immunization is the most effective way of prevention? & 81 & 19 \\
\hline Repetition of vaccine is necessary? & 72 & 28 \\
\hline Polio drops should not be given to children in diarrhea or fever? & 43 & 56 \\
\hline Breast feeding is not recommended for about 30 minutes after giving polio drops. & 25 & 75 \\
\hline Do you know about handicap/infantile paralysis due to polio? & 12 & 88 \\
\hline
\end{tabular}

This survey showed different reasons of parent's hesitancy towards polio vaccination, shown in Figure 3; multiple responses were selected by responders, so that there were a total of 326 responses; $23.9 \%$ participants gave their reason that it causes infertility in male children, whereas $16 \%$ had lack of trust on quality of vaccine and $16.6 \%$ reported lack of trust on health workers. Religious belief was also one of the reasons of hesitancy recorded to be $14.1 \%$. Some participants $(10.7 \%)$ recorded security issues as their reason of vaccine hesitancy; $9.5 \%$ responded non-compliant spouse as their reason, whereas 9.2\% considered that vaccination is not necessary.

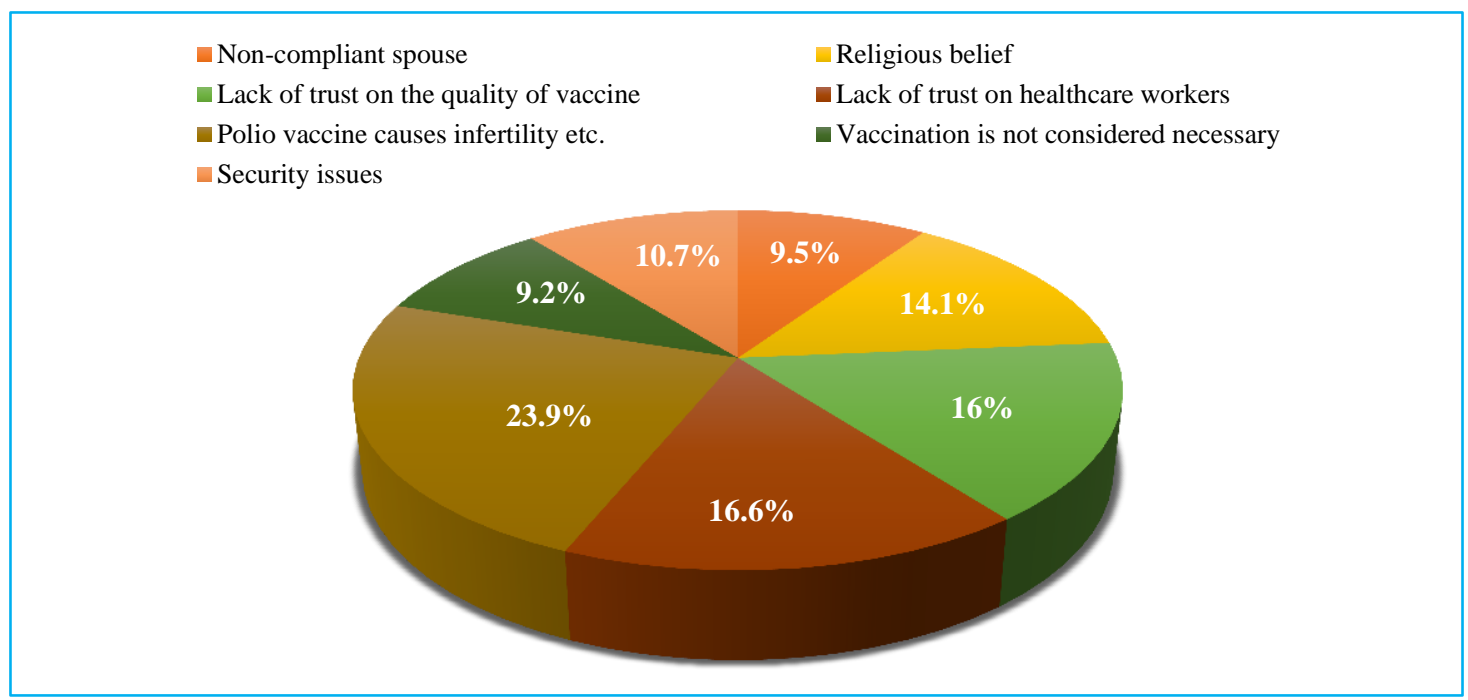

Figure 3: Reasons for hesitancy towards oral polio vaccine given by parents (total of $\mathbf{3 2 6}$ responses).

Table 2 compares the relationship of educational status of study participants with their reasons for vaccine hesitancy, and shows a trend in that the uneducated participants were more hesitant towards vaccination than educated ones, their major reasons being OPV causing male infertility, followed by lack of trust in healthcare workers, and on the quality of vaccines.

Table 2: Correlation between parental levels of education \& reasons for hesitancy (based on multiple responses).

\begin{tabular}{|c|c|c|c|c|c|c|c|}
\hline $\begin{array}{l}\text { Education level } \\
\text { of male parents }\end{array}$ & $\begin{array}{l}\text { Non-compliant } \\
\text { spouse }\end{array}$ & $\begin{array}{l}\text { Religious } \\
\text { belief }\end{array}$ & $\begin{array}{l}\text { Lack of trust } \\
\text { on the } \\
\text { quality of } \\
\text { vaccine }\end{array}$ & $\begin{array}{l}\text { Lack of } \\
\text { trust on } \\
\text { healthcare } \\
\text { workers }\end{array}$ & $\begin{array}{c}\text { Polio } \\
\text { vaccine } \\
\text { causes } \\
\text { infertility } \\
\text { etc. }\end{array}$ & $\begin{array}{l}\text { Vaccination } \\
\text { is not } \\
\text { considered } \\
\text { necessary }\end{array}$ & $\begin{array}{l}\text { Security } \\
\text { issues }\end{array}$ \\
\hline Nil & 16 & 21 & 24 & 28 & 41 & 10 & 14 \\
\hline Primary & 12 & 18 & 20 & 19 & 27 & 18 & 13 \\
\hline Secondary & 3 & 3 & 4 & 3 & 7 & 1 & 4 \\
\hline Tertiary & 0 & 1 & 1 & 1 & 1 & 0 & 1 \\
\hline Religious & 0 & 3 & 3 & 3 & 2 & 1 & 3 \\
\hline
\end{tabular}


Figure 4 correlates the ages of parents and their reasons of hesitancy, showing that the maximum percentage of hesitancy was seen in the age group of $31-40$ years. The main reasons recorded in every age group were that polio vaccine causes infertility in their children, followed by lack of trust in quality of vaccine.

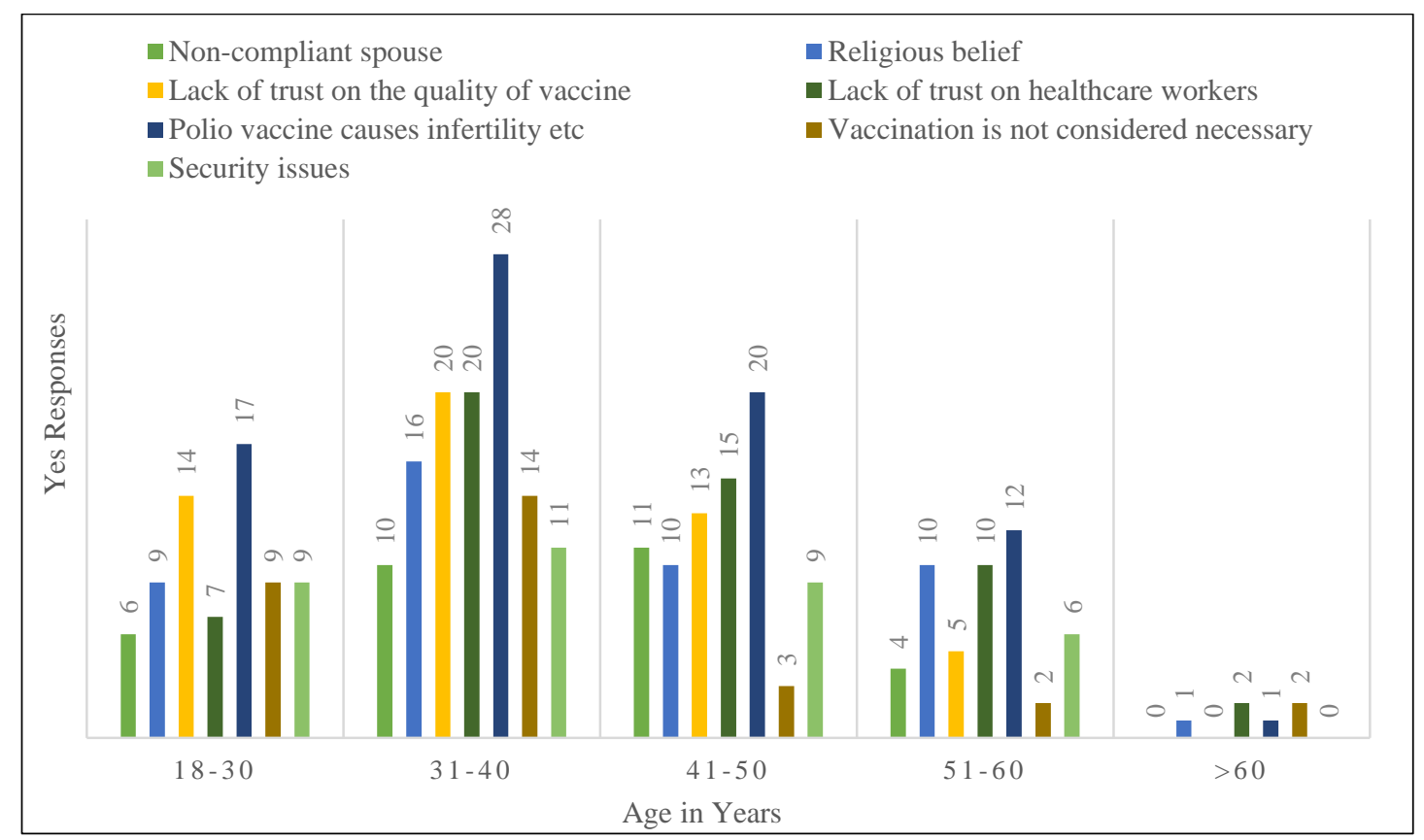

Figure 4: Association between age of respondents \& reasons for hesitancy towards oral polio vaccination $(\mathrm{n}=100)$.

\section{DISCUSSION}

This study, conducted in Federally Administered Tribal Area (FATA) of Khyber Pakhtunkhwa province of Pakistan called Khyber Agency showed that knowledge of male parents about the basic information regarding polio immunization was poor. The main reasons given by the study participants for vaccine hesitancy were risk of infertility, lack of trust on the quality of vaccine, and lack of trust on health workers; additionally, religious beliefs and security issues were found to be important for a smaller number of parents. When the education level of participants was compared with vaccine hesitancy or refusal, it came out that the vaccine refusal is more evident in low or noneducated profile parents.

The most common reasons for vaccine hesitancy given globally were the risk benefit of vaccines, awareness issues, religious, cultural, gender and socio-economic factors. ${ }^{11}$ Major issues were fear of side-effects, distrust on vaccines and lack of knowledge regarding vaccines and immunization services. This survey revealed that $29 \%$ of the countries assessed the level of confidence on immunization in their country, suggesting that vaccine confidence was an important issue. ${ }^{12}$

A similar study conducted in Peshawar and Quetta divisions of Pakistan $^{13}$ showed that $38.8 \%$ participants demonstrated good knowledge about polio. A huge percentage $(84.8 \%)$ of participants showed negative approach towards polio vaccination. Similar to this study, lack of education $(p<0.001)$ and rural residence $(\mathrm{p}<0.001)$ were the main reasons associated with polio hesitancy. The main reasons of vaccine hesitancy were false religious beliefs (39.06 \%), lack of knowledge (33.7 $\%$ ), fear of infertility $(32.16 \%)$ and security issues $(29.42 \%) .{ }^{13}$
A study conducted on the impact of polio vaccine hesitancy in south $\mathrm{Asia}^{8}$ showed that vaccine reluctance was just one of many barriers to polio eradication in South Asia. Factors of low vaccine confidence were local concern and mistrust that masked the immunization campaign in many parts of India. In Pakistan and Afghanistan, access to reaching communities with low polio immunization acceptance rates remained high along with the low confidence on oral polio vaccination. ${ }^{8}$

A survey conducted in India showed that vaccine hesitancy had remarkably been attributed to factors such as safety, rumors and controversies (vaccination leads to infertility), lack of awareness about benefits of vaccines and influence of stakeholders. These factors influence the perceptions of general population temporal and geographic barriers and personal attributes. ${ }^{14}$

A study conducted in Nigeria had also shown that Polio risk perception was low among study participants. The majority (59\%) of participants believed that vaccination was either not necessary or would not be helpful, and $30 \%$ thought it might be harmful. Religious beliefs were an important driver in the way people understood disease. Fifty-two percent of 48 respondents reported that illnesses were due to God's will and/or destiny and that only God could protect them against illnesses. Only a minority $(14 \%)$ of respondents indicated that polio was a significant problem in their community. ${ }^{15}$

A study from Bannu, Pakistan measured the parental vaccination refusal rate using the WHO SAGE Vaccine Hesitancy Survey Tool. The results showed that more than onequarter of parents refused vaccination of their children. The main associated factors were low education level, socioeconomic status and employment. Perceptions of parents about 
vaccines were determined using a Likert scale. The majority of parents $(60.6 \%)$ who refused vaccination believed that vaccination has serious adverse effects (p 0.005). The attitude towards polio vaccination showed that $19.4 \%$ of parents disagreed with doctors' advice to vaccinate their children. The huge proportions of study participants $(50.6 \%)$ disagreed with the statement that vaccination can keep their children safe. ${ }^{16}$

\section{LIMITATIONS}

A small sample size was selected through convenience sampling, so the study results cannot be generalized to the rest of Khyber Agency. Similarly, due to cultural values specific to Khyber Agency, the results may not represent the views based on cultural values of other regions of the province. Lastly, it was not possible to interview mothers because of prevailing social restrictions on meeting the female gender, so interviews reflect the views of the male parents only.

\section{CONCLUSION}

Lack of awareness/education turned out to be the main reason behind the misperception of male parents towards polio immunization in the Khyber Agency. Infertility and Religious beliefs were the major reasons of polio vaccine refusal.

\section{RECOMMENDATIONS}

To improve the confidence of oral polio vaccine in Pakistani communities, the national polio campaign should focus on two domains: one, to give due attention to vaccination and reaching out to non-accessible areas which were not accessed; two, to address the problem of vaccine refusal or hesitancy by creating awareness and counselling of the communities.

\section{REFERENCES}

1. Hussain SF, Boyle P, Patel P, Sullivan R Eradicating polio in Pakistan: An analysis of the challenges and solutions to this security and health issue. Global Health [Internet]. 2016;12(1):1-9. Available from: http://dx.doi.org/10.1186/s12992 016-0195-3

2. COUNTRY PROFILE: PAKISTAN Global Polio Eradication Initiative (GPEI) Status.

3. GPEI - Global Polio Eradication Initiative.

4. Larson HJ, Ghinai I, Aqeel T, Salman S, Ibrahim Q, Idrees J, et al. Lessons from polio eradication. Nature. 2011 May;473(7348):446-7.

5. Learning M, Cookbook R. National Polio Emergency Operations Centre (EOC), Islamabad, Pakistan. Natl Emerg Plan Plan Polio Erad 2017-2018.

6. WHO | Addressing Vaccine Hesitancy. WHO. 2016;

7. McKee C, Bohannon K. Exploring the reasons behind parental refusal of vaccines. Vol. 21, Journal of Pediatric Pharmacology and Therapeutics. 2018. p. 104-9.

8. Everist L. The Impact of Vaccine Hesitancy on the Polio Vaccine in South
Asia. Indep Study Proj Collect [Internet]. 2015; Available from: https://digitalcollections.sit.edu/isp_collect ion\%0Ahttps://digitalcollections.sit.edu/is p_collection/2106

9. Bhutta ZA, Boyle P, Patel P, Sullivan R, Bhutta Z, Salk D, et al. The last mile in global poliomyelitis eradication. Lancet. 2011 Aug;378(9791):549-52.

10. SteelFisher GK, Blendon RJ, Guirguis S, Brulé A, Lasala-Blanco N, Coleman M, et al. Threats to polio eradication in highconflict areas in Pakistan and Nigeria: A polling study of caregivers of children younger than 5 years. Lancet Infect Dis. 2015;15(10):1183-92.

11. Eskola J, Duclos P, Schuster M, MacDonald NE, Liang X, Chaudhuri M, et al. How to deal with vaccine hesitancy? Vaccine. 2015;33(34):4215-7.

12. Marti M, De Cola M, MacDonald NE, Dumolard L, Duclos P. Assessments of global drivers of vaccine hesitancy in 2014 - Looking beyond safety concerns. PLoS One. 2017;12(3):1-12

13. Khan MU, Ahmad A, Aqeel T, Salman S, Ibrahim Q, Idrees J, et al. Knowledge, attitudes and perceptions towards polio immunization among residents of two highly affected regions of Pakistan. BMC Public Health [Internet]. 2015;15(1):1-8 Available from: http://dx.doi.org/10.1186/s12889-0152471-1

14. Agrawal A, Kolhapure S, Di Pasquale A, Rai J, Mathur A. Vaccine Hesitancy as a Challenge or Vaccine Confidence as an Opportunity for Childhood Immunisation in India. Infect Dis Ther [Internet] 2020;9(3):421-32. Available from: https://doi.org/10.1007/s40121-02000302-9

15. Michael CA, Ogbuanu IU, Storms AD, Ohuabunwo CJ, Corkum M, Ashenafi S, et al. An assessment of the reasons for oral poliovirus vaccine refusals in Northern Nigeria. J Infect Dis. 2014;210(July 2017):S125-30

16. Khattak FA, Rehman K, Shahzad M, Arif N, Ullah N, Kibria Z, et al. Prevalence of Parental refusal rate and its associated factors in routine immunization by using WHO Vaccine Hesitancy tool: A Cross sectional study at district Bannu, KP, Pakistan. Int $\mathrm{J}$ Infect Dis [Internet] 2021;104:117-24. Available from: https://doi.org/10.1016/j.ijid.2020.12.029. 